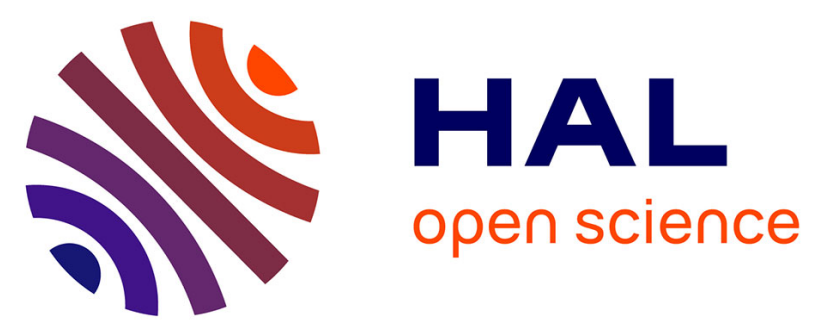

\title{
Observation of fast release of NO from ferrous d1 haem allows formulation of a unified reaction mechanism for cytochrome cd1 nitrite reductases.
}

Serena Rinaldo, Katharine Anne Sam, Nicoletta Castiglione, Valentina Stelitano, Alessandro Arcovito, Maurizio Brunori, James W.A. Allen, Stuart John Ferguson, Francesca Cutruzzolà

\section{To cite this version:}

Serena Rinaldo, Katharine Anne Sam, Nicoletta Castiglione, Valentina Stelitano, Alessandro Arcovito, et al.. Observation of fast release of NO from ferrous d1 haem allows formulation of a unified reaction mechanism for cytochrome cd1 nitrite reductases.. Biochemical Journal, 2011, 435 (1), pp.217-225. 10.1042/BJ20101615 . hal-00576988

\section{HAL Id: hal-00576988 https://hal.science/hal-00576988}

Submitted on 16 Mar 2011

HAL is a multi-disciplinary open access archive for the deposit and dissemination of scientific research documents, whether they are published or not. The documents may come from teaching and research institutions in France or abroad, or from public or private research centers.
L'archive ouverte pluridisciplinaire HAL, est destinée au dépôt et à la diffusion de documents scientifiques de niveau recherche, publiés ou non, émanant des établissements d'enseignement et de recherche français ou étrangers, des laboratoires publics ou privés. 


\title{
Observation of fast release of NO from ferrous $d_{1}$ haem allows formulation of a unified reaction mechanism for cytochrome $c d_{1}$ nitrite reductases
}

\author{
Serena Rinaldo * $\S$, Katharine A. Sam ${ }^{\dagger} \S$, Nicoletta Castiglione *, Valentina Stelitano *, Alessandro \\ Arcovito ${ }^{\ddagger}$, Maurizio Brunori ${ }^{*}$, James W. A. Allen ${ }^{\dagger}$, Stuart J. Ferguson ${ }^{\dagger}$, Francesca Cutruzzolà ${ }^{*} \|$ \\ From: *Dipartimento di Scienze Biochimiche "A. Rossi Fanelli"", Sapienza - Universitâ di Roma, P.le \\ A.Moro, 5 - 00185 Rome (Italy), ${ }^{\dagger}$ Department of Biochemistry, University of Oxford, South Parks \\ Road - Oxford OX1 3QU (UK), "Istituto di Biochimica e Biochimica Clinica, Università Cattolica del \\ Sacro Cuore, L.go F. Vito, 1- 00168 Rome (Italy)
}

$\S$ These authors contributed equally to this work

"Address correspondence to: Francesca Cutruzzolà, Dipartimento di Scienze Biochimiche "A. Rossi Fanelli" Sapienza - Università di Roma, P.le A.Moro 5 - Rome (Italy). Phone 0039-0649910713; Fax 0039-064440062; E-mail: francesca.cutruzzola@uniroma1.it

Stuart Ferguson, Department of Biochemistry - University of Oxford. Phone +44 (0)1865 613299; Email: stuart.ferguson@bioch.ox.ac.uk

\begin{abstract}
Cytochrome $c d_{1}$ nitrite reductase is a haem-containing enzyme responsible for the reduction of nitrite into nitric oxide (NO), a key step in the anaerobic respiratory process of denitrification. The active site of cytochrome $c d_{1}$ contains the unique $d_{1}$ haem cofactor, from which NO must be released. In general, reduced hemes bind NO tightly relative to oxidised hemes. Here we present experimental evidence that the reduced $d_{1}$ heme of cytochrome $c d_{1}$ from Paracoccus pantotrophus releases NO rapidly $\left(\mathrm{k}=65-200 \mathrm{~s}^{-1}\right)$; this result suggests that NO release is the rate-limiting step of the catalytic cycle (turnover number $=72 \mathrm{~s}^{-1}$ ). We also demonstrate using a complex of the $d_{1}$ haem and apomyoglobin, that the rapid dissociation of NO is largely controlled by the $d_{1}$ haem cofactor itself. We present a reaction mechanism proposed to be applicable to all cytochromes $c d_{1}$ and conclude that the $d_{1}$ haem has evolved to have low affinity for NO, as compared to other ferrous haems.
\end{abstract}

Short title: reactivity of $d_{1}$ haem with nitric oxide

Keywords: nitric oxide, hemoprotein, nitrite reductase, Pseudomonas aeruginosa, Paracoccus pantotrophus, nitrite. 


\section{INTRODUCTION}

Denitrification is an anaerobic respiratory process, found widely in both autotrophic and heterotrophic microrganisms [1], in which oxidized nitrogen compounds such as nitrate and nitrite are used as electron acceptors for energy production. Denitrification has been implicated in the virulence of several bacterial species, including Brucella [2], Pseudomonas [3] and Neisseria [4]. In Pseudomonas aeruginosa, denitrification is also a source of nitric oxide (NO), a crucial signaling molecule during infection and growth of bacteria in anaerobic biofilms [5]. The biological role of NO under physiological and pathological situations is well-known [6]; a critical aspect of the biology of NO is the interaction of this molecule with the haem group. The general rule is that NO binds much more strongly to ferrous than to the ferric haem, a consideration that imposes mechanistic constraints on many proteins that synthesize or bind NO [7-9].

In a wide range of denitrifying bacteria the reduction of nitrite $\left(\mathrm{NO}_{2}^{-}\right)$to $\mathrm{NO}$ is carried out by periplasmic cytochrome $c d_{1}$ nitrite reductase (cytochrome $c d_{1}$ ) [1], an homodimeric, haem-containing protein with one $c$-haem and one $d_{1}$ haem per monomer [10] (Supplementary data - Fig. S1). The $d_{1}$ haem (3,8-dioxo-17-acrylate-porphyrindione) is an unusual macrocycle with partial saturation and a set of oxo, methyl, and acrylate substituents, which makes it unique among tetrapyrroles (Supplementary data - Fig. S2). The best-studied examples of cytochrome $c d_{1}$ nitrite reductases are those from Paracoccus pantotrophus and P. aeruginosa [10]. The $c$-haem moiety of cytochrome $c d_{1}$ accepts electrons from soluble electron carriers, such as $c$-type cytochromes (cyt $c_{550}$, cyt $c_{551}$, cyt $c_{554}$ ) or copper proteins, like azurin or pseudoazurin [10]. The electrons are transferred from the $c$-haem of cytochrome $c d_{1}$ to the $d_{1}$ haem (of the same monomer), where the substrate binds and is converted to NO. Nitrite coordination to $P$. pantotrophus cytochrome $c d_{1}$ is via the $\mathrm{N}$-atom as shown by crystallography [11]. The reduction of nitrite by cytochrome $c d_{1}$ involves binding of the substrate to the reduced $d_{1}$ haem iron $\left(d_{1}{ }^{2+}\right)$, followed by one-electron reduction to yield $\mathrm{NO}$, which is then released [1]. The last step in the catalytic cycle of cytochrome $c d_{1}$, i.e. NO dissociation, has been subject of much debate [12-14]. Recently it was shown that NO is released rapidly from the ferrous $d_{1}$ haem $\left(k_{\mathrm{off}}=71 \mathrm{~s}^{-1}\right)$ of $P$. aeruginosa cytochrome $c d_{1}[15,16]$. This surprising result suggested that the affinity for $\mathrm{NO}$ of the ferrous $d_{1}$ haem in the enzyme from $P$. aeruginosa was 3-4 orders of magnitude smaller $\left(K_{\mathrm{a}} \sim 10^{7} \mathrm{M}^{-1}\right)$ than for many other hemoproteins such as myoglobin and hemoglobin $\left(K_{\mathrm{a}} \sim\right.$ $\left.10^{11}-10^{12} \mathrm{M}^{-1}\right)$ [7] and cytochrome $a a_{3}$ oxidase $\left(K_{\mathrm{a}} \sim 10^{10} \mathrm{M}^{-1}\right)$ [17].

In order to clarify whether the capability to release NO rapidly from ferrous $d_{1}$ haem iron is a general property of cytochrome $c d_{1}$ nitrite reductases, we have investigated the reactivity with $\mathrm{NO}$ of ferrous $P$. pantotrophus cytochrome $c d_{1}$. There are a number of significant differences between the enzymes from $P$. pantotrophus and P.aeruginosa. In steady state turnover of nitrite, $P$. pantotrophus cytochrome $c d_{1}$ displays a considerably higher $k_{\text {cat }}\left(72 \mathrm{~s}^{-1}\right.$ at $\mathrm{pH} 7.0$ and $\left.25^{\circ} \mathrm{C}\right)$ [18] than the value for P.aeruginosa cytochrome $c d_{1}\left(6 \mathrm{~s}^{-1}\right.$ at $\mathrm{pH} 7.0$ and $\left.20^{\circ} \mathrm{C}\right)$ [15]. Also, the internal electron transfer between the $c$-heme and the $d_{1}$ heme occurs several orders of magnitude faster in $P$. pantotrophus cytochrome $c d_{1}\left(\sim 1000 \mathrm{~s}^{-1}\right)$ [14,19] than in P.aeruginosa cytochrome $\mathrm{cd}_{1}\left(3 \mathrm{~s}^{-1}\right)$ [20]. These differences raised the question as to whether NO release from ferrous $\mathrm{d}_{1}$ haem of the $P$. pantotrophus enzyme would be sufficiently rapid to be catalytically competent.

We report here that NO is released rapidly from $P$. pantotrophus cytochrome $c d_{1}$; the value of the NO dissociation rate suggests that this process represents the rate-limiting step of the catalytic cycle. The finding that the reaction mechanism for cytochrome $c d_{1}$ involves fast NO dissociation from ferrous $d_{1}$ haem supports the idea that the chemical properties of this unique cofactor are crucial for activity. To corroborate this hypothesis we have also investigated the kinetics of NO dissociation from ferrous $d_{1}$ haem complexed with sperm whale apomyoglobin, in order to probe NO reactivity in a protein environment different from cytochrome $c d_{1}$. We found that ferrous $d_{1}$ haem bound to apomyoglobin releases NO rapidly, confirming the leading role of this cofactor in controlling reactivity of cytochromes $c d_{1}$ with NO.

\section{EXPERIMENTAL}

Preparation of $P$. pantotrophus cytochrome $c d_{1^{-}}$P. pantotrophus was grown in anaerobic 
conditions at $37{ }^{\circ} \mathrm{C}$. Cytochrome $c d_{1}$ was purified from the periplasm of the cells according to the method of Moir et al. [21] as modified by Koppenhöfer et al. [22]. The purity of the enzyme was determined by the $\mathrm{R}_{\mathrm{z}}$ value $\left(\mathrm{A}_{406(\mathrm{Ox})} / \mathrm{A}_{280}\right)$ and all cytochrome $c d_{1}$ used in this work had an $\mathrm{R}_{\mathrm{z}}>1.25$. The concentration of the enzyme was determined at $406 \mathrm{~nm}$ for the oxidized enzyme and $418 \mathrm{~nm}$ for the reduced, using the respective extinction coefficients of $142.5 \mathrm{mM}^{-1} \mathrm{~cm}^{-1}$ and $161.5 \mathrm{mM}^{-1} \mathrm{~cm}^{-1}[19$, 22]. These extinction coefficients refer to the concentration of the enzyme monomer; throughout this work, the enzyme concentration will be given as monomer concentration and thus catalytic constants will refer to turnover per monomer. Fully reduced cytochrome $c d_{1}$ was prepared by reduction with sodium dithionite in an anaerobic glove box; the excess reductant was removed by passing the enzyme down a desalting column packed with P6-DG resin (BioRad) and equilibrated with $50 \mathrm{mM}$ potassium phosphate buffer $\mathrm{pH} 7.0$ in the presence of $5 \mathrm{mM}$ sodium ascorbate and $13 \mu \mathrm{g} / \mathrm{ml}$ ascorbate oxidase (SIGMA). The reduced NO-bound and cyanide-bound derivatives were obtained after addition of either a stoichiometric amount of NO, or excess KCN, to the reduced protein. Stock solutions of $\mathrm{NO}$ were prepared by equilibrating $\mathrm{NO}$ with buffer at $25^{\circ} \mathrm{C}$, assuming the aqueous concentration of $\mathrm{NO}$ at 1 atm to be $1.9 \mathrm{mM}$. All spectra were recorded in a JASCO V650 spectrophotometer.

A summary of the relevant spectra of $P$. pantotrophus cytochrome $c d_{1}$ derivatives, together with a scheme of the $c$-haem and the $d_{1}$ haem ligands in each derivative is shown in Supplementary Data (Fig. S3). It was previously reported that, upon reduction of the $c$-haem, the iron coordination changes from His-His to His-Met [11]. The latter coordination (His-Met) does not change during turnover; reversion to the His-His state occurs very slowly (minutes) and only in the absence of ligands or substrates [23]. Therefore, the change in coordination of the $c$-haem is not expected to occur during the time range of the kinetics reported in the present paper.

Stopped-flow measurements- All the stopped flow experiments described in this work were carried out anaerobically in $50 \mathrm{mM}$ potassium phosphate buffer $\mathrm{pH} 7.0$ in the presence of $5 \mathrm{mM}$ sodium ascorbate and $13 \mu \mathrm{g} / \mathrm{ml}$ ascorbate oxidase (SIGMA), added to scavenge possible oxygen contamination. The concentration of the samples in the different experiments is given "after mixing" (hereinafter a.m.): a 1:1 dilution was always used in the symmetric mixing apparatus. All the experiments were performed with an Applied Photophysics stopped-flow apparatus (DX.17MV, Applied Photophysics, Leatherhead, UK). To follow the rate of NO dissociation a monochromatic light source was used in the single wavelength acquisition mode; the use of the diode array acquisition mode was limited because photodissociation of NO is known to affect the rate. All the kinetic analysis was carried out with the IgorPro program (Wavemetrics).

In the experiments described below, the spectral analysis of the events occurring at the $d_{1}$ haem was carried out following the absorbance changes at wavelengths above $600 \mathrm{~nm}$, in order to avoid overlap with the $c$-haem, which does not contribute to this region of the spectrum. In the experimental conditions used in this work, there is no evidence that ligands such as nitrite and cyanide bind to the $c$-haem.

In order to determine the dissociation rate of NO from the reduced $d_{1}$ haem, the reduced NO-bound cytochrome $c d_{1}(3 \mu \mathrm{M})$ was rapidly mixed in the stopped flow apparatus with excess potassium cyanide $(0.08,0.12,0.2,1,5,10,15$ and $100 \mathrm{mM}$ a.m.), and the formation of the reduced-cyanide bound derivative was followed at different wavelengths. Under these conditions, cyanide displaces NO by binding to the reduced $d_{1}$ haem.

To probe if NO dissociation from the fully reduced enzyme can be facilitated by the substrate, the reduced NO-bound cytochrome $c d_{1}(3.5 \mu \mathrm{M})$ was rapidly mixed in the stopped flow apparatus with sodium nitrite $(3 \mathrm{mM})$, and the reaction was followed in the diode array acquisition mode. This approach has been chosen in order to gain spectral information on the species involved, although we are aware that the observed rate can be slightly faster than under monochromatic light.

Under these conditions the following reaction occurs and nitrite binding is rate limited by NO dissociation:

Cytochrome $c d_{1}-\mathrm{NO}+\mathrm{NO}_{2}^{-}-->$cytochrome $c d_{1}-\mathrm{NO}_{2}{ }^{-}+\mathrm{NO}-->$ catalysis

As a control, the reduced ligand-free $(3.5 \mu \mathrm{M})$ enzyme was mixed with the same amounts of nitrite as above in the presence of excess ascorbate. The similarity of the latter reaction in terms of species 
involved and time course to previously published results [24] indicates that excess ascorbate does not alter the reaction mechanism.

Laser photolysis measurements- A $4.5 \mu \mathrm{M}$ protein solution in $50 \mathrm{mM}$ potassium phosphate buffer $(\mathrm{pH} 7)$ at room temperature was reduced anaerobically as described above and then transferred to a fully filled gas-tight cuvette (Hellma) with four transparent windows; the path length along the direction of the probe light was $1 \mathrm{~cm}$ and the path length in the orthogonal direction was $4 \mathrm{~mm}$. Different volumes of a stock NO solution were added anaerobically to produce the reduced NO-bound derivative in the concentration range $(25-100 \mu \mathrm{M})$. The set-up used for photolysis experiments is home-built and has been described elsewhere [25]; every kinetic trace was the result of an average of 256 time courses at a single wavelength, each obtained after a single laser shot. The time course was followed at $460 \mathrm{~nm}$, a wavelength where the spectrum of the reduced cytochrome $c d_{1}$ is dominated by the contribution of $d_{1}$ haem. Data analysis was performed by globally fitting all the kinetic traces at different final NO concentrations.

Haem $d_{1}$-apomyoglobin experiments- Haem $d_{1}$-apomyoglobin (hereinafter $\mathrm{Mb} d_{1}$ ) was prepared after reconstitution of sperm whale apomyoglobin (prepared according to [26]) using the $d_{1}$-haem extracted from wild type $P$. aeruginosa cytochrome $c d_{1}$, as reported previously [27]. Mb $d_{1}$ preparation and kinetic experiments were carried out in $40 \mathrm{mM}$ sodium phosphate buffer $\mathrm{pH}$ 6.9.

The reduced $\mathrm{Mb} d_{1}$ was prepared anaerobically by adding $5 \mathrm{mM}$ sodium ascorbate to the oxidized protein in degassed buffer at $20^{\circ} \mathrm{C}$, in the presence of $13 \mu \mathrm{g} / \mathrm{ml}$ of ascorbate oxidase as oxygen scavenger. The reduced NO-bound derivative was obtained after addition of $100 \mu \mathrm{M}$ NO solution (prepared as reported above). All spectra were recorded in a JASCO V550 spectrophotometer.

To determine the NO dissociation rate constant, the reduced NO-bound-Mbd$d_{1}$ was mixed anaerobically in a gas-tight cuvette containing $5 \mathrm{mM}$ sodium dithionite and $\sim 500 \mu \mathrm{M} \mathrm{CO}$; the process was followed by recording the spectrum $(400-700 \mathrm{~nm})$. The formation of the CO-bound complex [27] was complete within 2 min. To measure the kinetics of $\mathrm{NO}$ dissociation, the NO-bound-Mb $d_{1}$ was mixed in the stopped-flow with a buffer solution containing $1 \mathrm{mM} \mathrm{CO}$ and $5 \mathrm{mM}$ sodium dithionite (before mixing) (three independent experiments). The kinetic process was followed at $451 \mathrm{~nm}$; the time course was fitted with a single exponential equation.

\section{RESULTS}

The rate constant for binding of NO to reduced P. pantotrophus cytochrome $c d_{1}$. The association rate constant for the binding of NO to reduced $P$. pantotrophus cytochrome $c d_{1}$ was determined by laser flash photolysis at $\mathrm{pH} 7.0$ under anaerobic conditions at $25^{\circ} \mathrm{C}$ (Fig. 1). Time courses were followed at $460 \mathrm{~nm}$ in the presence of different $\mathrm{NO}$ concentrations $(25,50,75$ and $100 \mu \mathrm{M})$. The small absorbance change observed in the experiment is consistent with the low photolysis yield of the NO species, as previously observed with $P$. aeruginosa cytochrome $c d_{1}$ [15]. The global fit of the kinetic traces at different $\mathrm{NO}$ concentrations yields a value of $k_{\mathrm{on}(\mathrm{NO})}=3.5 \pm 0.3 \times 10^{8} \mathrm{M}^{-1} \mathrm{~s}^{-1}$ (Table I).

The rate constant for dissociation of NO from reduced P. pantotrophus cytochrome $c d_{l}$. To measure NO dissociation, we took advantage of the unusually high affinity for cyanide of reduced cytochrome $c d_{1}$, which can be exploited to displace NO from the ferrous $d_{1}$ haem [15]. It was previously shown that ferrous $P$. pantotrophus cytochrome $c d_{1}$ binds cyanide relatively tightly $\left(K_{\mathrm{d}}=\right.$ $0.7 \pm 0.2 \times 10^{-6} \mathrm{M}$ at $\mathrm{pH} 7.0$ ) (Table I) [28], although the corresponding association and dissociation rate constants were not determined. We determined these rate constants (Supplementary Figs 4 and 5) since they are necessary to calculate the NO dissociation rate constant in the cyanide-NO displacement experiment and found values of: $k_{\mathrm{on}(\mathrm{CN})}=5.9 \pm 0.1 \times 10^{5} \mathrm{M}^{-1} \mathrm{~s}^{-1}$ and $k_{\mathrm{off}(\mathrm{CN})}=0.4 \pm 0.02$ $\mathrm{s}^{-1}$ (Table I). These results yield a $K_{\mathrm{d}}=0.68 \mu \mathrm{M}$, in excellent agreement with the equilibrium value previously reported [28].

The NO dissociation time course at $20^{\circ} \mathrm{C}$ and $\mathrm{pH} 7.0$ was time-resolved by mixing reduced NObound $P$. pantotrophus cytochrome $c d_{1}$ with excess cyanide $(0.08-100 \mathrm{mM})$ in the stopped-flow instrument and following the kinetics at $627 \mathrm{~nm}$ (Fig. 2), a wavelength characteristic of the ferrous $d_{1}$ heme-CN complex (Figure S2) and where the $c$-heme does not absorb. The time course of formation of the cyanide derivative (Fig. 2A) was biphasic under all conditions. The biphasicity cannot be ascribed to the cyanide binding process, which is always monophasic (Fig. S4). 
The values of the rate constants for both phases, $k_{1}$ and $k_{2}$, have been plotted as a function of ligand concentration (Fig. 2B). At low $\left[\mathrm{CN}^{-}\right]$, the two phases have equal amplitudes, suggesting that the two monomers of cytochrome $c d_{1}$ possibly react at different rates; at high $\left[\mathrm{CN}^{-}\right]$, some amplitude of the first phase is lost in the dead time of the instrument because the reaction is too fast. The data have been analyzed using the replacement model described in [26]:

$$
\mathrm{R}=\frac{\mathrm{k}_{\text {off(NO) }} \mathrm{k}_{\text {on(CN) }}\left[\mathrm{CN}^{-}\right]+\mathrm{k}_{\text {off(CN) }} \mathrm{k}_{\text {on(NO) }}[\mathrm{NO}]}{\mathrm{k}_{\text {on(CN) }}\left[\mathrm{CN}^{-}\right]+\mathrm{k}_{\text {on(NO) }}[\mathrm{NO}]}
$$

The two rate constants for NO dissociation from reduced Pp-cytochrome $c d_{1}$ are as follows: $k_{1}=$ $201.2 \pm 11.4 \mathrm{~s}^{-1}$ and $k_{2}=64.9 \pm 2.3 \mathrm{~s}^{-1}$ for the fast and slow processes, respectively (Table I).

Displacement of NO by nitrite from reduced P. pantotrophus cytochrome $c d_{1}$. Both the ferrous NObound and, for comparison, the ferrous enzyme, were mixed anaerobically with excess nitrite $(3 \mathrm{mM})$ in the stopped flow apparatus (at $20^{\circ} \mathrm{C}$ and $\mathrm{pH} \mathrm{7.0).} \mathrm{The} \mathrm{time} \mathrm{courses} \mathrm{at} 551$ and $660 \mathrm{~nm}$, representative of the $c$ - and $d_{1}$ haems respectively, are shown in Fig. 3 (upper panels) for the reducedNO bound enzyme (black circles) and the reduced unligated enzyme (empty triangles). It is clear that the kinetic phase seen within the first $20 \mathrm{~ms}$ in the experiment with the reduced-NO bound species is absent in the reaction with the unligated reduced enzyme. Spectral analysis shows that this fast phase involves $c$-haem oxidation and synchronous formation of a transient at the $d_{1}$ haem, occurring at about $100 \mathrm{~s}^{-1}$ (Fig. 3A and B, respectively). At longer times $(>20 \mathrm{~ms}$ ) the time courses of the two experiments are superimposable (Fig. 3, upper panels). Analysis of the spectra (Fig. 3C) shows that the first observable species (at $1 \mathrm{~ms}$ ) is different in the two experiments, whereas at longer times (> $0.1 \mathrm{~s})$ the spectra superimpose, suggesting that the same derivative is formed on the latter timescale. The final species, which is formed at $\sim 20 \mathrm{~s}^{-1}$, is very similar to that previously observed in the reaction of reduced P. pantotrophus cytochrome $c d_{1}$ with nitrite [24]. We conclude that during the first $20 \mathrm{~ms}$ nitrite displaces NO and reacts with the reduced protein populating an intermediate whose formation is rate-limited by NO dissociation. The synchronous $c$ haem oxidation indicates that this intermediate is formed as nitrite is reduced to NO; afterwards this species decays as when the initially reduced but unligated enzyme reacts with nitrite.

The rate of dissociation of $N O$ from reduced $d_{1}$ haem complexed with apomyoglobin. The low affinity towards NO displayed by cytochrome $c d_{1}$ could be due to the presence of the unique $d_{1}$ haem and/or the structure of the haem binding pocket. In order to assess the role of $d_{1}$ haem in controlling per se the affinity for NO, we have measured the NO dissociation rate constant from ferrous $d_{1}$ haem complexed with apomyoglobin from sperm whale $\left(\mathrm{Mb} d_{1}\right)$.

As previously published, the $\hat{d}_{1}$ haem cofactor combines with apomyoglobin to form a stable complex; several ferric and ferrous derivatives have been spectroscopically characterized [27]. Steup et al. [27] suggested that the $d_{1}$ haem was coordinated by a strong field ligand that they assigned as a histidine residue; however, no static or kinetic characterization with NO was reported. Since the peculiarity of the reactivity with $\mathrm{NO}$ of the $d_{1}$ haem in cytochrome $c d_{1}$ resides in the fast release of the ligand, we have measured the dissociation rate of NO from the reduced $\mathrm{Mb} d_{1}$ complex. Sperm whale apomyoglobin was complexed with the $d_{1}$ haem; the spectral properties of the complex were identical to those previously published [27]. Fig. 4A shows the spectra of the ascorbate-reduced state (thin line) and of the stable derivative obtained by reacting the latter species with $100 \mu \mathrm{M}$ NO (bold line), with peaks at 445 and $644 \mathrm{~nm}$. To determine the NO dissociation rate constant, the NO derivative was mixed anaerobically in a gas-tight cuvette with $5 \mathrm{mM}$ sodium dithionite and $\sim 500 \mu \mathrm{M}$ CO (final concentrations) and the spectrum $(400-700 \mathrm{~nm}$ ) was recorded. The first spectrum (obtained 1.5 minutes after mixing) shows peaks at 452 and $642 \mathrm{~nm}$ (Fig. 4A, dashed line) suggesting that the CObound species had already formed. The spectrum did not change significantly during the time of the experiment $(\sim 30 \mathrm{~min})$, but the shoulder at $590 \mathrm{~nm}$ broadened (data not shown), suggesting that two CO-bound species were formed which slowly re-equilibrated, in agreement with previous evidence [27]. Since binding of $\mathrm{CO}$, and thus dissociation of NO, could not be time-resolved in the spectrophotometer, the same reaction was followed by stopped-flow, at $451 \mathrm{~nm}$ (Fig. 4B). The reaction had a half-time of $\sim 350 \mathrm{~ms}$ and the observed absorbance change corresponded to $92 \%$ of that 
expected (Fig. 4A, bold and dashed line). The majority of the transition (Fig. 4B, continuous line) occurred at $k_{\text {off }}=2.0 \pm 0.4 \mathrm{~s}^{-1}$; this reaction was found to be CO concentration independent (data not shown).

\section{DISCUSSION}

The reaction of NO with haems plays an important role in controlling cellular physio-pathological processes $[7-9,17]$. The fact that NO binds strongly to ferrous haem, albeit reversibly at extremely low free NO concentrations, imposes mechanistic constraints on many proteins that synthesize or bind NO. The enzymatic turnover of cytochrome $c d_{1}$ nitrite reductase, in which nitrite is converted to NO, also demands the fast release of the product to avoid inhibition.

In the present paper, we aim at understanding whether the unique $d_{1}$ haem, where nitrite reduction occurs, has a role in controlling the release of NO. Therefore we have measured the reactivity of the $d_{1}$ haem with $\mathrm{NO}$ in the physiological context, i.e. the cytochrome $c d_{1}$ enzyme from $P$. pantotrophus and in a non-native protein environment, provided by apomyoglobin. The data presented here provide novel mechanistic insights on the reaction mechanism of cytochrome $c d_{1}$ and allow us to draw a common scheme that is applicable to this whole class of enzymes (Fig. 5).

Nitric oxide release is rapid in ferrous cytochrome $c d_{1}$ : relevance to the catalytic cycle. The major novel conclusion of this work is that fast NO dissociation from the ferrous $d_{1}$ haem is a common feature of cytochrome $c d_{1}$ nitrite reductases. This conclusion is supported by the observation that NO dissociation from the reduced $d_{1}$ haem of P. pantotrophus cytochrome $c d_{1}$ is fast (Fig.2 and Table I) $\left(\mathrm{k}_{\text {off }}=200 \mathrm{~s}^{-1}\right.$ and $65 \mathrm{~s}^{-1}$ for the biphasic dissociation); these data agree well with previous results for the $P$. aeruginosa cytochrome $c d_{1}$ where NO dissociation occurred at $70 \mathrm{~s}^{-1}$ [15] (Table I). As a consequence of the greater $k_{\text {off }}$ from reduced $d_{1}$ haem, the $K_{\mathrm{d}}$ for NO in cytochrome $c d_{1}$ is orders of magnitude larger than in other haemoproteins $[7,17,29]$ (Table I).

The rapid NO dissociation from cytochrome $c d_{1}$ nitrite reductases strongly suggests that NO release from ferrous $d_{1}$ haem of cytochrome $c d_{1}$ is a plausible step in the catalytic cycle. Therefore the mechanism previously proposed [15] and summarized in Fig. 5, is a reasonable general catalytic cycle for all cytochromes $c d_{1}$. Notably, it is also essentially the simplest reaction cycle one can draw for these enzymes. This interpretation explains why the $d_{1}{ }^{3+}$-NO derivative of $P$. pantotrophus cytochrome $c d_{1}$ is a very long-lived species in the absence of excess reductant [14,30]; it also agrees with previous ultra-fast ( $\mu$ s) kinetic studies on the same enzyme showing that intramolecular $c$ haem to $d_{1}$ haem electron transfer triggered product release [31]. All available data indicate that $P$. pantotrophus cytochrome $c d_{1}$ only works efficiently in the presence of substrate and electron donors $[18,30,32,33]$, i.e. it gets "stuck" with NO bound in the absence of reducing equivalents. It has long been a puzzle why an enzyme that catalyses a one-electron reduction requires two redox centres (the $c$ and $d_{1}$ hemes). Electron donation to cytochrome $c d_{1}$ from partner proteins occurs only via the $c$ heme. A reaction mechanism where nitrite is first reduced to NO at the $d_{1}$ heme, oxidizing that heme, but in which the $d_{1}$ heme must be re-reduced (by the $c$-heme) to allow NO release, would explain the need for two redox centres.

The data presented here also suggest that, after the release of NO, the ferrous enzyme is competent to start a new catalytic cycle; therefore the reduced NO-bound $P$. pantotrophus cytochrome $c d_{1}$ is not irreversibly inhibited. This is supported by the kinetic experiment in which the fully reduced-NO bound cytochrome $c d_{1}$ is mixed with nitrite: in this experiment, a complex reaction involving both electron transfer between the two redox centres (as seen by the oxidation of $c$-haem, Figure 3A) and chemistry at the $d_{1}$ haem (Figure 3B) is observed. The relevant observation is that an intermediate species (populated at $100 \mathrm{~s}^{-1}$ ) could be observed with spectroscopic features (around $660 \mathrm{~nm}$ ) similar to those previously observed when the reduced $P$. pantotrophus cytochrome $c d_{1}$ was reacted with nitrite in a freeze-quench experiment [31]. In the kinetic experiment presented here, the formation of this transient species (Fig. 3) supports the idea that, after the release of NO, the ferrous enzyme can start a new catalytic cycle. The ability of the P. pantotrophus cytochrome $c d_{1}$ to release NO without undergoing significant product inhibition is also consistent with earlier steady state experiments in which a linear rate of NO production occurred up to tens of micromolar concentrations [34]. 
Another novel mechanistic insight into the reaction with nitrite catalysed by cytochrome $c d_{1}$ is the assignment of the rate-determining step. In P. pantotrophus cytochrome $c d_{1}$ the slower phase of NO dissociation $\left(k_{\text {off }}=65 \mathrm{~s}^{-1}\right.$; Figure 2$)$ occurs with a rate that is very similar to the overall $k_{\text {cat }}\left(72 \mathrm{~s}^{-1}\right.$ per $d_{1}$ haem [18]), indicating that this process is likely to represent the rate-limiting step of the reaction. However, for $P$. aeruginosa cytochrome $c d_{1}$ the rate-determining step is likely to be the intramolecular electron transfer from the $c$ haem to the $d_{1}$ haem, since the reported electron transfer rate $\left(1-4 \mathrm{~s}^{-1}\right)$ is similar to the turnover number $\left(6 \mathrm{~s}^{-1}\right)[20,35]$. Thus, in $P$. aeruginosa cytochrome $c d_{1}$, the relatively slow formation of ferrous $d_{1}$ haem-NO would be followed by a more rapid dissociation of NO.

Although more speculative, we note that analysis of NO dissociation from P. pantotrophus cytochrome $c d_{1}$ may also suggest that, in this enzyme, the two monomers dissociate NO at different rates (NO dissociation is biphasic and each kinetic phase corresponds to $\sim 50 \%$ of the total absorbance change). These data are in agreement with previous kinetic experiments with nitrite which were interpreted in terms of anticooperativity of the two monomers [31]. Even though the mechanism of such anticooperativity is yet to be explained, intrinsic asymmetry of cytochrome $c d_{1}$ is suggested and supported by evidence obtained from ligand binding experiments $[28,36]$, pre-steady state kinetic study with nitrite [31], intramolecular electron transfer [20,37] and potentiometric titrations [38, 39]. Moreover, in the many X-ray crystal structures of $P$. pantotrophus cytochrome $c d_{1}$ and its ligandbound derivatives, the two monomers are always different $[11,28,40]$.

Role of the $d_{1}$ haem in NO release. The other novel outcome of this work is that fast NO dissociation from ferrous haem iron is largely due to the presence of the unique $d_{1}$ haem cofactor. The role of ferrous $d_{1}$ haem in controlling NO dissociation was analysed in a different protein environment, i.e. the $d_{1}$ haem complexed with apomyoglobin $\left(\mathrm{Mb} d_{1}\right)$. In ferrous $\mathrm{Mb} d_{1}$, we observe a single $\mathrm{NO}$ dissociation process occurring at $2 \mathrm{~s}^{-1}$ (Fig.4), a rate which is about 3-5 orders of magnitude greater then that measured for native ferrous myoglobin which contains $b$ haem (Fe-protoporphyrin IX) (Table I) [7]. Given these results and taking into account that both $\mathrm{Mb} d_{1}$ and cytochrome $c d_{1}$ share a common proximal histidine ligand, we conclude that the $d_{1}$ haem is designed to release NO relatively rapidly. It is known that $\mathrm{NO}$ is a good $\pi$-acceptor and, in general, an important contribution to the strength of NO binding to the ferrous haem iron can arise from electron donation from the $\mathrm{t} 2 \mathrm{~g}$ orbitals on the iron. The two electron withdrawing carbonyl groups on the $d_{1}$ haem ring (see Supplementary Fig. S2) might weaken such electron donation to NO.

There are previous observations indicating that the ring structure of the $d_{1}$ haem confers on the $\mathrm{Fe}$ atom other properties that are distinct from those of protoporphyrin IX. The ferrous state of $d_{1}$ haem binds anions, including the substrate nitrite and the inhibitor cyanide, unusually strongly and, strikingly, more strongly than the ferric state (Table I) [32]. This also correlates with the presence of two electron withdrawing carbonyl groups on the $d_{1}$ haem ring. Another feature of the $d_{1}$ haem ring is that in the ferric state this cofactor shows a peculiar ordering of the energy levels of the d orbitals [41]; the latter property is shared with other haems in which the porphyrin ring is partially saturated (haem $d$ in Escherichia coli and sirohaem) [42,43]. Clearly, a range of advanced spectroscopic and theoretical studies, outside the scope of the present work, needs to be applied to fully understand how the $d_{1}$ haem ring is tuned, in the ferrous state, to bind anions unusually strongly, but nitric oxide unusually weakly, in order to catalyse the reduction of nitrite. The consequence is that whereas $a$ priori one might have expected a haem enzyme to bind nitrite to, and release nitric oxide from, the ferric state, the opposite strategy has evolved.

The higher NO dissociation rate measured for cytochromes $c d_{1}$ (up to $200 \mathrm{~s}^{-1}$ ) (as compared to $\mathrm{Mb} d_{1}$ ) may reflect a feature in the $d_{1}$ haem pocket that optimizes NO release. A possible mechanism may include the conformational change seen in $P$. pantotrophus cytochrome $c d_{1}$ and thought to be implicated in catalysis [44]; this change involves Y197 on the proximal side of the $d_{1}$ haem pocket and the hinge region (residues 132-136) connecting the c- and the $d_{1}$ haem domains. However, mutation of these residues (Y197F and P134F/P135F) has no significant effect on the enzymatic activity (Zajicek and Ferguson, unpublished data) and thus it is unlikely to control NO release. Therefore the (relatively small) contribution of the protein moiety to the control of NO release is yet to be identified at the molecular level. 
Concluding remarks. The present work allows the formulation of a straightforward, unified reaction mechanism for cytochrome $c d_{1}$ nitrite reductases, a class of enzymes studied for over 50 years (Figure 5). The experiments reported here strongly suggest that fast NO dissociation from ferrous haem iron is largely due to the presence of the unique $d_{1}$ haem cofactor and that enzyme inhibition by $\mathrm{NO}$ is unlikely to be relevant under physiological conditions. The evidence underscores that the reactivity of porphyrins with NO can be modulated very extensively by the functional groups present on the haem macrocycle, information of general significance in light of the emerging important biological functions of nitrite as a source of NO under hypoxic conditions [45].

\section{ACKNOWLEDGEMENTS}

A. Bellelli (Rome, Italy) is gratefully acknowledged for useful discussions on the kinetic experiments.

\section{FUNDING}

Funds from the Ministero della Università of Italy [20074TJ3ZB, RBRN07BMCT] and from the University of Rome La Sapienza to F.C. and M.B. are gratefully acknowledged. K.A.S. thanks St Edmund Hall, Oxford for the award of a W.R. Miller Junior Research Fellowship. The Biotechnology and Biological Sciences Research Council supported JWAA through a David Phillips Fellowship [grant number BB/D019753/1] and SJF through project grants. 


\section{REFERENCES}

1 Zumft, W. G. (1997) Cell biology and molecular basis of denitrification. Microbiol. Mol. Biol. Rev. . 61, 533-616

2 Baek, S. H., Rajashekara, G., Splitter, G. A. and Shapleigh, J. P. (2004) Denitrification genes regulate Brucella virulence in mice. J Bacteriol. 186, 6025-6031

3 Van Alst, N. E., Picardo, K. F., Iglewski, B. H. and Haidaris, C. G. (2007) Nitrate sensing and metabolism modulate motility, biofilm formation, and virulence in Pseudomonas aeruginosa. Infect Immun. 75, 3780-3790

4 Barth, K. R., Isabella, V. M. and Clark, V. L. (2009) Biochemical and genomic analysis of the denitrification pathway within the genus Neisseria. Microbiology. 155, 4093-4103

5 Hassett, D. J., Sutton, M. D., Schurr, M. J., Herr, A. B., Caldwell, C. C. and Matu, J. O. (2009) Pseudomonas aeruginosa hypoxic or anaerobic biofilm infections within cystic fibrosis airways. Trends Microbiol. 17, 130-138

6 Ignarro, L. J. (2009) Nitric Oxide (Second Edition) Biology and Pathobiology. Academic Press

7 Moore, E. G. and Gibson, Q. H. (1976) Cooperativity in the dissociation of nitric oxide from hemoglobin. J. Biol. Chem. . 251, 2788-2794

8 Brown, G. C. and Cooper, C. E. (1994) Nanomolar concentrations of nitric oxide reversibly inhibit synaptosomal respiration by competing with oxygen at cytochrome oxidase. FEBS Lett. 356, 295-298.

9 Boon, E. M. and Marletta, M. A. (2005) Ligand discrimination in soluble guanylate cyclase and the H-NOX family of heme sensor proteins. Curr Opin Chem Biol. 9, 441-446

10 Rinaldo, S. and Cutruzzolà, F. (2007) Nitrite reductases in denitrification. in Bothe H., Ferguson S., Newton W. E., ed ; Biology of the Nitrogen Cycle, Amsterdam: Elsevier. p. 37-55

11 Williams, P. A., Fülöp, V., Garman, E. F., Saunders, N. F., Ferguson, S. J. and Hajdu, J. (1997) Haem-ligand switching during catalysis in crystals of a nitrogen-cycle enzyme. Nature. 389, 406-412

12 Averill, B. A. (1996) Dissimilatory Nitrite and Nitric Oxide Reductases. Chem. Rev. 96, 2951-2964

13 Silvestrini, M. C., Tordi, M. G., Musci, G. and Brunori, M. (1990) The reaction of Pseudomonas nitrite reductase and nitrite. A stopped-flow and EPR study. J. Biol. Chem. 265, 1178311787

14 George, S. J., Allen, J.W., Ferguson, S.J. and Thorneley, R.N. (2000) Time-resolved infrared spectroscopy reveals a stable ferric heme-NO intermediate in the reaction of Paracoccus pantotrophus cytochrome cd1 nitrite reductase with nitrite. J. Biol. Chem. 275, 33231-33237

15 Rinaldo, S., Arcovito, A., Brunori, M. and Cutruzzolà, F. (2007) Fast dissociation of nitric oxide from ferrous Pseudomonas aeruginosa cd1 nitrite reductase. A novel outlook on the catalytic mechanism. J. Biol. Chem. 282, 14761-14767

16 Rinaldo, S., Brunori, M. and Cutruzzolà, F. (2007) Nitrite controls the release of nitric oxide in Pseudomonas aeruginosa cd1 nitrite reductase. Biochem. Biophys. Res. Commun. 363, 662-666

17 Sarti, P., Giuffrè, A., Forte, E., Mastronicola, D., Barone, M. C. and Brunori, M. (2000) Nitric oxide and cytochrome c oxidase: mechanisms of inhibition and NO degradation. Biochem. Biophys. Res. Commun. 274, 183-187

18 Richter, C. D., Allen, J. W., Higham, C. W., Koppenhofer, A., Zajicek, R. S., Watmough, N. J. and Ferguson, S. J. (2002) Cytochrome cd1, reductive activation and kinetic analysis of a multifunctional respiratory enzyme. J. Biol. Chem. 277, 3093-3100

19 Kobayashi, K., Koppenhöfer, A., Ferguson, S. J. and Tagawa, S. (1997) Pulse radiolysis studies on cytochrome cd1 nitrite reductase from Thiosphaera pantotropha: evidence for a fast intramolecular electron transfer from c-heme to d1-heme. Biochemistry. 36, 13611-13616 
20 Farver, O., Brunori, M., Cutruzzolà, F., Rinaldo, S., Wherland, S. and Pecht, I. ( 2009) Intramolecular electron-transfer in Pseudomonas aeruginosa cd1 nitrite reductase - thermodynamics and kinetics. Biophys. J. 96, 2849-2856

21 Moir, J. W. B., Baratta, D., Richardson, D. J. and Ferguson, S. J. (1993) The purification of a cd1-type nitrite reductase from, and the absence of a copper-type nitrite reductase from, the aerobic denitrifier Thiosphaera pantotropha; the role of pseudoazurin as an electron donor. Eur. J. Biochem. 212, 377-385

22 Koppenhöfer, A., Little, R. H., Lowe, D. J., Ferguson, S. J. and Watmough, N. J. (2000) Oxidase reaction of cytochrome cd(1) from Paracoccus pantotrophus. Biochemistry. 39, 4028-4036

23 Allen, J. W., Watmough, N. J. and Ferguson, S. J. (2000) A switch in heme axial ligation prepares Paracoccus pantotrophus cytochrome cd 1 for catalysis. Nat. Struct. Biol. . 7, 885-888

24 Sam, K. A., Fairhurst, S. A., Thorneley, R. N., Allen, J. W. and Ferguson, S. J. (2008) Pseudoazurin dramatically enhances the reaction profile of nitrite reduction by Paracoccus pantotrophus cytochrome cd1 and facilitates release of product nitric oxide. J Biol Chem. . 283, 12555-12563

25 Arcovito, A., Gianni, S., Brunori, M., Travaglini-Allocatelli, C. and Bellelli, A. (2001) Fast coordination changes in cytochrome $\mathrm{c}$ do not necessarily imply folding. J. Biol. Chem. 276, 4107341078

26 Antonini, E. and Brunori, M. (1971). North-Holland Publishing Company, Amsterdam London

27 Steup, M. B. and Muhoberac, B. B. (1989) Preparation and spectral characterization of the heme d1.apomyoglobin complex: an unusual protein environment for the substrate-binding heme of Pseudomonas cytochrome oxidase. . J Inorg Biochem. 37, 233-257

28 Jafferji, A., Allen, J. W., Ferguson, S. J. and Fulop, V. (2000) X-ray crystallographic study of cyanide binding provides insights into the structure-function relationship for cytochrome cd1 nitrite reductase from Paracoccus pantotrophus. J. Biol. Chem. 275, 25089-25094

29 Borisov, V. B., Forte, E., Sarti, P., Brunori, M., Konstantinov, A. A. and Giuffrè, A. (2007) Redox control of fast ligand dissociation from Escherichia coli cytochrome bd. Biochem. Biophys. Res. Commun. 355, 97-102

30 Sam, K. A., Tolland, J.D., Fairhurst, S.A., Higham, C.W., Lowe, D.J., Thorneley, R.N., Allen, J.W. and Ferguson, S.J. (2008) Unexpected dependence on pH of NO release from Paracoccus pantotrophus cytochrome cd(1). Biochem. Biophys. Res. Commun. 371, 719-723

31 Sam, K. A., Strampraad, M. J., de Vries, S. and Ferguson, S. J. (2008) Very early reaction intermediates detected by microsecond time scale kinetics of cytochrome cd1-catalyzed reduction of nitrite. J. Biol. Chem. . 283, 27403-27409

32 Zajicek, R. S., Cartron, M. L. and Ferguson, S. J. (2006) Probing the unusual oxidation/reduction behavior of Paracoccus pantotrophus cytochrome cd(1) nitrite reductase by replacing a switchable methionine heme iron ligand with histidine. Biochemistry. 45, 11208-11216

33 Sam, K. A., Fairhurst, S.A., Thorneley, R.N., Allen, J.W. and Ferguson, S.J. (2008) Pseudoazurin dramatically enhances the reaction profile of nitrite reduction by Paracoccus pantotrophus cytochrome cd 1 and facilitates release of product nitric oxide. J. Biol. Chem. 283, 12555-12563

34 Carr, G. J., Page, M. D. and Ferguson, S. J. (1989) The energy-conserving nitric-oxidereductase system in Paracoccus denitrificans. Distinction from the nitrite reductase that catalyses synthesis of nitric oxide and evidence from trapping experiments for nitric oxide as a free intermediate during denitrification. Eur J Biochem. 179, 683-692

35 Cutruzzolà, F., Brown, K., Wilson, E. K., Bellelli, A., Arese, M., Tegoni, M., Cambillau, C. and Brunori, M. (2001) The nitrite reductase from Pseudomonas aeruginosa: essential role of two active-site histidines in the catalytic and structural properties. Proc. Natl. Acad. Sci. U S A. 98, 22322237

36 Sun, W., Arese, M., Brunori, M., Nurizzo, D., Brown, K., Cambillau, C., Tegoni, M. and Cutruzzolà, F. (2002) Cyanide binding to cd(1) nitrite reductase from Pseudomonas aeruginosa: role of the active-site His369 in ligand stabilization. Biochem. Biophys. Res. Commun. 291, 1-7 
37 Farver, O., Kroneck, P. M., Zumft, W. G. and Pecht, I. (2003) Allosteric control of internal electron transfer in cytochrome cd1 nitrite reductase. Proc. Natl. Acad. Sci. U S A. 100, 7622-7625.

38 Blatt, Y., and Pecht, I. (1979) Allosteric cooperative interactions among redox sites of Pseudomonas cytochrome oxidase. Biochemistry. 18, 2917-2922

39 Koppenhöfer, A., Turner, K. L., Allen, J. W., Chapman, S. K. and Ferguson, S. J. (2000) Cytochrome cd(1) from Paracoccus pantotrophus exhibits kinetically gated, conformationally dependent, highly cooperative two-electron redox behavior. Biochemistry. 39, 4243-4249

40 Fulop, V., Moir, J. W., Ferguson, S. J. and Hajdu, J. (1995) The anatomy of a bifunctional enzyme: structural basis for reduction of oxygen to water and synthesis of nitric oxide by cytochrome cd1. Cell. 81, 369-377

41 Cheesman, M. R., Ferguson, S. J., Moir, J. W., Richardson, D. J., Zumft, W. G. and Thomson, A. J. (1997) Two enzymes with a common function but different heme ligands in the forms as isolated. Optical and magnetic properties of the heme groups in the oxidized forms of nitrite reductase, cytochrome cd1, from Pseudomonas stutzeri and Thiosphaera pantotropha. Biochemistry. 36, 16267-16276

42 Frankenberg, N., Moser, J. and Jahn, D. ( 2003) Bacterial heme biosynthesis and its biotechnological application. Appl Microbiol Biotechnol. 63, 115-127

43 Tanaka, R. and Tanaka, A. (2007) Tetrapyrrole biosynthesis in higher plants. Ann. Rev. Plant Biol. 58, 321-346

44 Sjögren, T. and Hajdu, J. (2001) The Structure of an alternative form of Paracoccus pantotrophus cytochrome cd(1) nitrite reductase. J Biol Chem.. 276, 29450-29455

45 van Faassen, E. E., Bahrami, S., Feelisch, M., Hogg, N., Kelm, M., Kim-Shapiro, D. B., Kozlov, A. V., Li, H., Lundberg, J. O., Mason, R., Nohl, H., Rassaf, T., Samouilov, A., SlamaSchwok, A., Shiva, S., Vanin, A. F., Weitzberg, E., Zweier, J. and Gladwin, M. T. (2009) Nitrite as regulator of hypoxic signaling in mammalian physiology. Med Res Rev 29, 683-741

46 Gladwin, M. T. and Kim-Shapiro, D. B. (2008) The functional nitrite reductase activity of the heme-globins. Blood 112, 2636-2647

47 Boffi, A., Ilari, A., Spagnuolo, C. and Chiancone, E. (1996) Unusual affinity of cyanide for ferrous and ferric Scapharca inaequivalvis homodimeric hemoglobin. Equilibria and kinetics of the reaction. Biochemistry. 35, 8068-8074

48 Olivas, E., De Waal, D. J. and Wilkins, R. G. (1977 ) Reduction of metmyoglobin derivatives by dithionite ion. J. Biol. Chem. . 252, 4038-4042

49 Azizi, F., Kielbasa, J. E., Adeyiga, A. M., Maree, R. D., Frazier, M., Yakubu, M., Shields, H., King, S. B. and Kim-Shapiro, D. B. (2005) Rates of nitric oxide dissociation from hemoglobin. Free. Radic. Biol. Med. . 39, 145-151

50 Brunori, M., Antonini, G., Castagnola, M. and Bellelli, A. (1992) Cooperative cyanide dissociation from ferrous hemoglobin. J. Biol. Chem. 267, 2258-2263

51 Stitt, F. and Coryell, C. D. (1939) Magnetic study of the equilibrium between ferrohemoglobin, cyanide ion and cyanide ferrohemoglobin. J. Am. Chem. Soc. 61, 1263-1266

52 Cutruzzolà, F., Rinaldo, S., Castiglione, N., Giardina, G., Pecht, I. and Brunori, M. (2009) Nitrite reduction: a ubiquitous function from a pre-aerobic past. Bioessays. 31, 885-891

53 Muhoberac, B. B. and Wharton, D. C. (1983) Electron paramagnetic resonance study of the interaction of some anionic ligands with oxidised Pseudomonas cytochrome c oxidase. J. Biol. Chem. 258, 3019-3027

54 Silvestrini, M. C., Colosimo, A., Brunori, M., Walsh, T. A., Barber, D. and Greenwood, C. (1979) A re-evaluation of some basic structural and functional properties of Pseudomonas cytochrome oxidase. Biochem J. . 183, 701-709 


\section{TABLE I}

Kinetic parameters for nitrite reduction and for $N O$ and cyanide binding to and dissociation from reduced cytochrome cd ${ }_{1}$ nitrite reductases. For comparison, the catalytic parameters for proteins able to catalyze the reduction of nitrite to NO [52] and containing a b-type haem are also shown.

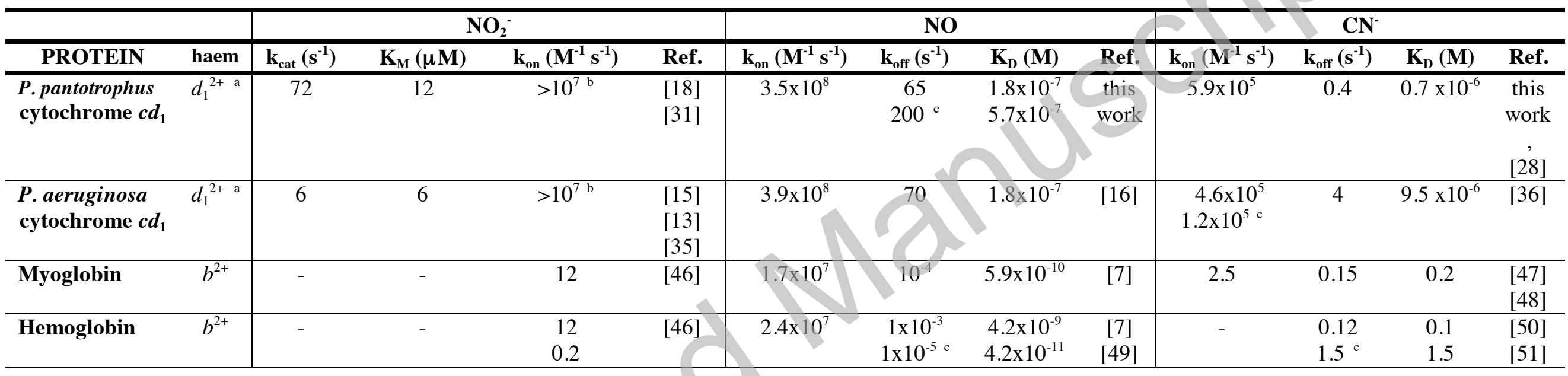

${ }^{a}$ Cytochrome $c d_{1}$ nitrite reductase binds the selected ligands to the ferrous state of the $d_{1}$ heme. Anions such as nitrite or cyanide bind to ferric $d_{1}$ heme with very low affinity ( $\mathrm{K}_{\mathrm{D}}$ nitrite $\sim 1 \mathrm{M}$ ) [53]. NO reacts slowly with the ferric enzyme by binding to the $d_{1}$ heme and then reducing it to produce the $d_{1}{ }^{2+}-\mathrm{NO}$ derivative; this autoreductive phenomenon is $\mathrm{pH}$ dependent [54]. The kinetic parameters reported in the table are at $\mathrm{pH} 7.0$ and $20-25^{\circ} \mathrm{C}$; under these experimental conditions, none of the ligands used react with the $c$-heme. However, at more acidic $\mathrm{pH}$, nitrosylation of the $c$-heme (by NO or nitrite after reduction via $d_{1}$ heme) was reported to occur [23].

${ }^{\mathrm{b}}$ Nitrite binding occurs very rapidly and cannot be directly measured; therefore the values in the table refer to estimates reported in the cited references.

${ }^{\mathrm{c}}$ Two kinetic constants are reported in all experiments where a biphasic kinetics was observed (see present work and corresponding references).

Licenced copy. Copying is not permitted, except with prior permission and as allowed by law.

(c) 2011 The Authors Journal compilation ( 2011 Portland Press Limited 


\section{FIGURE LEGENDS}

Fig. 1. Time course of NO recombination with fully reduced P. pantotrophus cytochrome $c d_{1}$. The reaction was initiated by photodissociation of $\mathrm{NO}$ with a laser pulse at $532 \mathrm{~nm}$; the recombination was monitored at $460 \mathrm{~nm}$ at four different $\mathrm{NO}$ concentrations, i.e. 100, 75, 50 and $25 \mu \mathrm{M}$. Only traces at $100 \mu \mathrm{M}$ and $25 \mu \mathrm{M}$ are shown for clarity (grey thin lines), together with the results obtained by globally fitting all the traces (black dotted and solid lines, respectively). As described in Experimental Procedures, every kinetic trace is the result of an average of 256 time courses, each obtained after a single laser shot. Experimental conditions: cytochrome $c d_{1} 4.5 \mu \mathrm{M}, 25^{\circ} \mathrm{C}$ and $50 \mathrm{mM}$ potassium phosphate $\mathrm{pH} 7.0$ containing $5 \mathrm{mM}$ ascorbate and $13 \mu \mathrm{g} / \mathrm{ml}$ ascorbate oxidase.

Fig. 2. Dissociation of NO from fully reduced NO-bound P. pantotrophus cytochrome $c d_{1}$ obtained by displacement with excess cyanide.

(A) The dissociation time course was followed after mixing fully reduced NO-bound cytochrome $c d_{1}$ $(6 \mu \mathrm{M})$ with excess potassium cyanide $(0.08,0.12,0.2,1,5,10,15$ and $100 \mathrm{mM})$ in the stopped flow apparatus. The kinetic data were collected in the single wavelength acquisition mode in order to minimize NO photodissociation. The kinetics was followed at $627 \mathrm{~nm}$ (absorption maximum of the cyanide bound $d_{1}$ heme (there is no absorbance from the $c$-heme at this wavelength)) and the time course fitted with a double exponential equation (dashed line).

(B) Plot of the observed NO displacement rate constant from reduced cytochrome $c d_{1}$ as a function of cyanide concentration; each kinetic phase (see above) was plotted independently ( $\mathrm{k}_{1}=$ black circles; $\mathrm{k}_{2}=$ open circles). The data are fitted using the replacement model (thin line) [26]; the equation contains the cyanide $k_{\text {on }}$ and $k_{\text {off }}$ and the NO $k_{\text {on }}$ values measured independently in this work. The values of three independent measurements at each cyanide concentration are reported.

Experimental conditions: $20^{\circ} \mathrm{C}$ and $50 \mathrm{mM}$ potassium phosphate $\mathrm{pH} 7.0$ containing $5 \mathrm{mM}$ ascorbate and $13 \mu \mathrm{g} / \mathrm{ml}$ ascorbate oxidase.

Fig. 3. Dissociation of NO from reduced P. pantotrophus cytochrome $c d_{1}$ induced by displacement with nitrite.

(Upper panels): Time course of the reaction of $3.5 \mu \mathrm{M}$ cytochrome $c d_{1}$, either reduced NO-bound (black circles) or reduced (empty triangles), mixed with $3 \mathrm{mM}$ nitrite. The reaction was followed at wavelengths representative of the $c$-haem $\left(551 \mathrm{~nm}\right.$, panel A) and of the $d_{1}$ heme $(660 \mathrm{~nm}$, panel B). In the reaction of the reduced-NO bound enzyme, the decrease at $551 \mathrm{~nm}$ (black circles in Fig.3A) indicates oxidation of the $c$-heme, whereas the increase of absorption at $660 \mathrm{~nm}$ (black circles in Fig.3B) indicates the formation of a transient species. The solid lines represent fits of the data with a single or double exponential equation, respectively. The arrows indicate 20 and $400 \mathrm{~ms}$ after mixing (see below).

(Panel C) Optical spectra collected at 1, 20 and $400 \mathrm{~ms}$ after mixing with nitrite the reduced NObound (continous line) and the reduced cytochrome $c d_{1}$ (dotted line).

Experimental conditions: $20^{\circ} \mathrm{C}$ and $50 \mathrm{mM}$ potassium phosphate $\mathrm{pH} 7.0$ containing $5 \mathrm{mM}$ ascorbate and $13 \mu \mathrm{g} / \mathrm{ml}$ ascorbate oxidase.

Fig 4. Dissociation of NO from ferrous $d_{1}$ heme complexed with sperm whale apomyoglobin $\left(\mathrm{Mb} d_{1}\right)$. The displacement of $\mathrm{NO}$ was measured in the presence of excess $\mathrm{CO}$ and dithionite [26] (at $20{ }^{\circ} \mathrm{C}$ and $\mathrm{pH}$ 6.9); under these conditions $\mathrm{CO}$ competes with $\mathrm{NO}$ for binding to the reduced $d_{1}$ heme iron and the kinetics are rate-limited by NO dissociation. (Panel A) Absorbance spectra of ascorbatereduced $\mathrm{Mb} d_{1}$ (thin line) and of the corresponding NO-bound derivative (bold line). The latter species was mixed anaerobically in a gas-tight cuvette with $5 \mathrm{mM}$ sodium dithionite as NO scavenger and $\sim 500 \mu \mathrm{M} \mathrm{CO}$, and the spectrum $(400-700 \mathrm{~nm})$ was recorded (dashed line). This spectrum did not change significantly over the following $\sim 30 \mathrm{~min}$. (Panel B) Reaction of ascorbate-reduced $\mathrm{Mb} d_{1}$ mixed with $1 \mathrm{mM} \mathrm{CO}$ and $5 \mathrm{mM}$ dithionite (before mixing) in the stopped flow apparatus. The observed time course at $451 \mathrm{~nm}$ (grey circles) represents the decay of the reduced NO-bound derivative; the time course was fitted with a single-exponential equation (solid line). Experimental 
conditions: $20^{\circ} \mathrm{C}$ and $40 \mathrm{mM}$ potassium phosphate $\mathrm{pH} 6.9$ containing $5 \mathrm{mM}$ ascorbate and $13 \mu \mathrm{g} / \mathrm{ml}$ ascorbate oxidase. The final protein concentrations (after mixing) were the same in Panels A and B.

Fig. 5. Proposed reaction mechanism for the catalytic cycle of cytochrome $c d_{1}$ nitrite reductases.

The catalytic cycle (panel A) is illustrated starting from the fully reduced enzyme (species 1) which binds the substrate nitrite yielding the Michaelis complex (species 2) [10,11,31]. Nitrite binding and reduction involves two conserved His residues [11] whose mutation was shown to affect the activity of P.aeruginosa cytochrome $c d_{1}$ [35] (see panel B for a scheme of the active site). Transfer of one electron from the $d_{1}$ heme to nitrite produces NO bound to the oxidised heme iron (species 3 ) and a water molecule, which is released (oxidised hemes are shown in grey). NO release from species $\mathbf{3}$ was not observed [14]. All available data suggest that NO dissociation occurs from the fully reduced NObound enzyme (species 5) in both $P$. pantotrophus and $P$. aeruginosa cytochromes $c d_{1}$ (present work and [15], respectively). Species 5 is formed via species $\mathbf{4}$ in two steps: transfer of an electron from the $c$-heme to the $d_{1}$-heme, followed by reduction of the $c$-heme by an external electron donor. The physiological reductants of cytochrome $c d_{1}$ are small cytochromes $c$ (such as $P$. aeruginosa cytochrome $c_{551}$ or $P$. pantotrophus cytochrome $c_{550}$ ) or copper proteins (such as pseudoazurin in $P$. pantotrophus) [10], which specifically transfer the electron only to the $c$-heme.

After NO dissociation from species 5, the fully reduced enzyme is re-formed and enters a new catalytic cycle. The present data does not allow us to rule out that NO dissociation may occur from the mixed valence nitrosylated protein (species 4); this would be difficult to measure due to the intrinsic redox instability of the mixed valence species [54]. The scheme presented here refers to a single monomer of the enzyme; various data (see Discussion and [31]) imply the possibility of cooperativity between monomers during the catalytic cycle, but this is thought to affect the relative rates of catalytic steps in each monomer, not the steps themselves. 


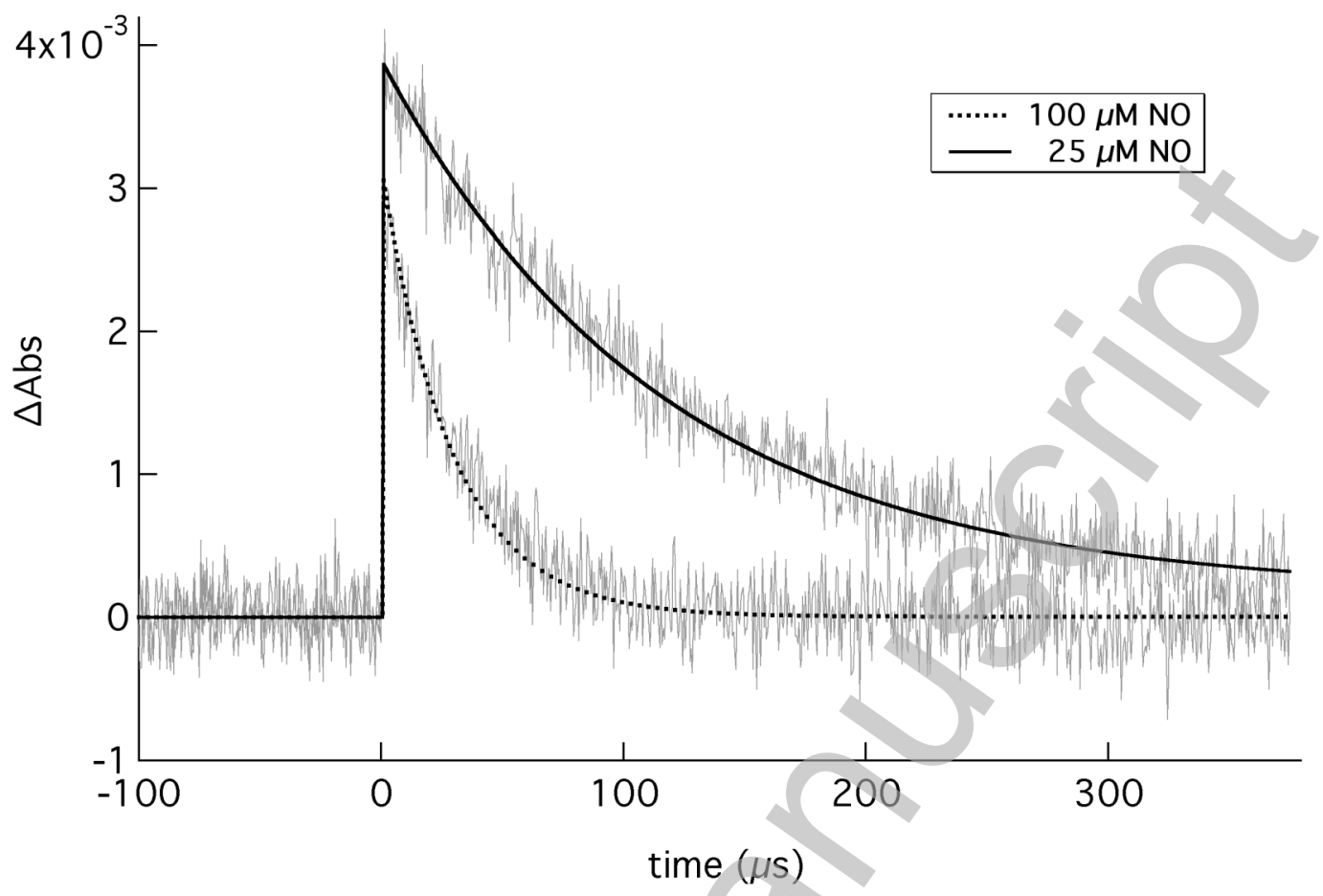

FIGURE 1 
A

B
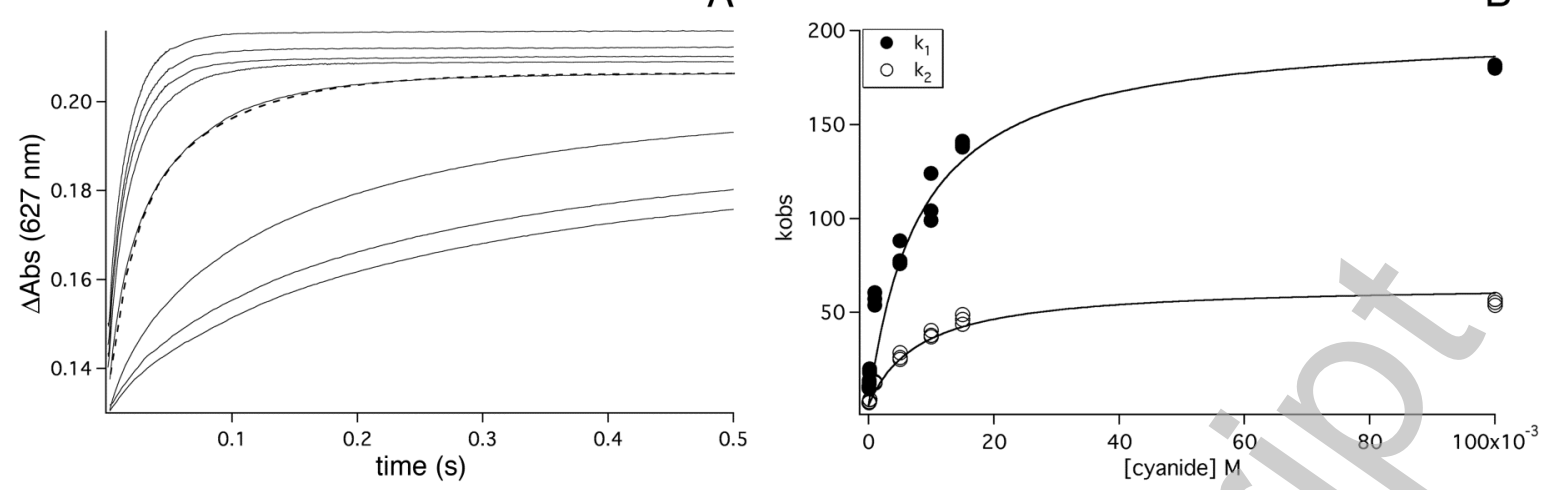

FIGURE 2

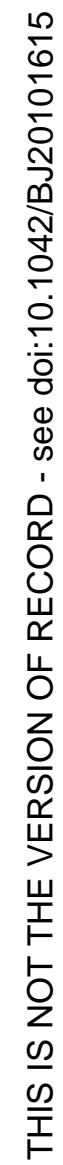



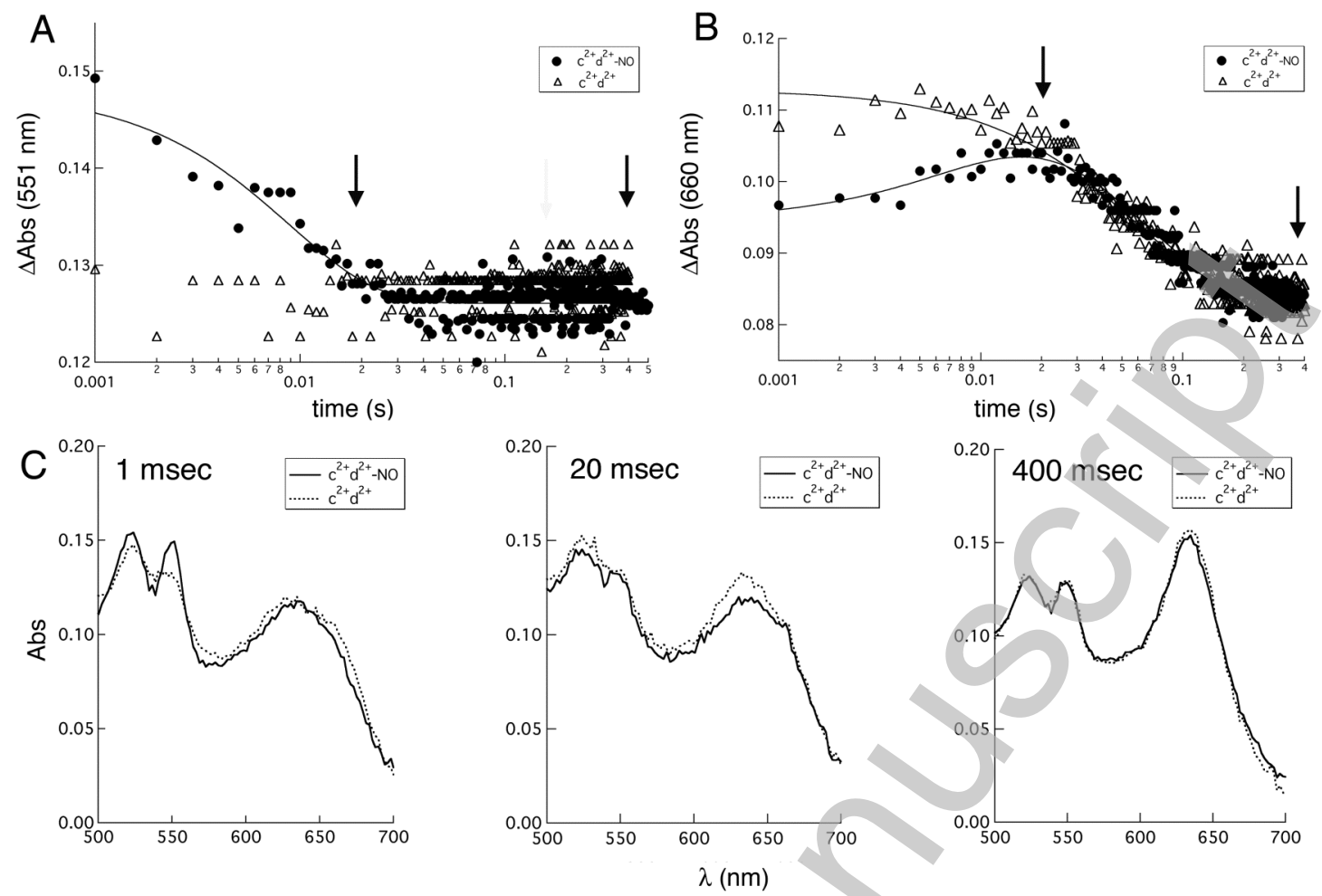

FIGURE 3

Licenced copy. Copying is not permitted, except with prior permission and as allowed by law. (C) 2011 The Authors Journal compilation (c) 2011 Portland Press Limited 

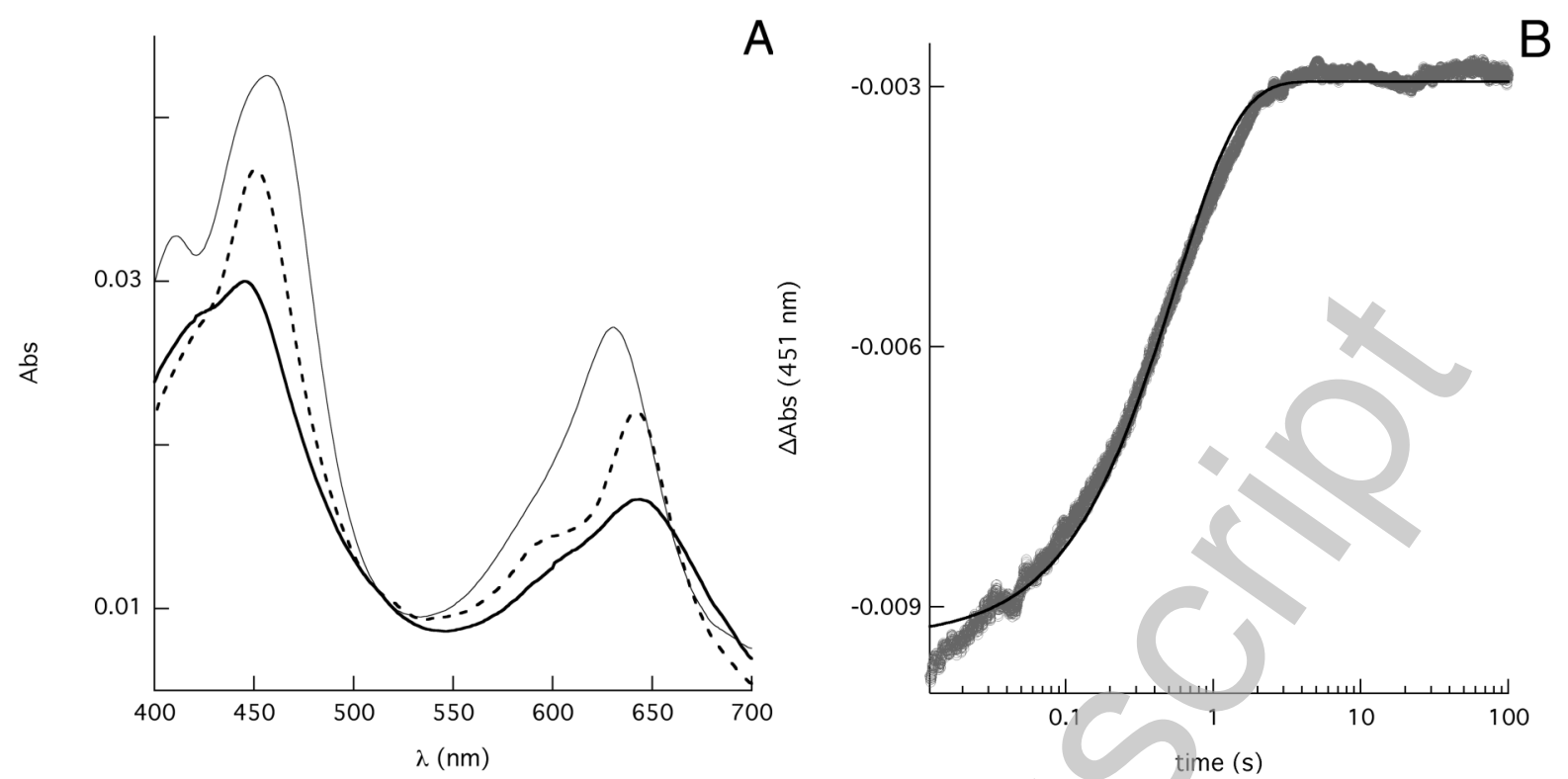

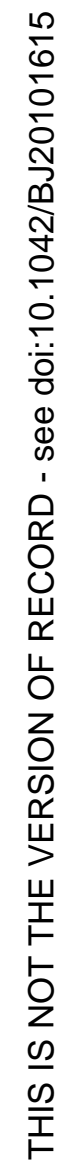

FIGURE 4 
A

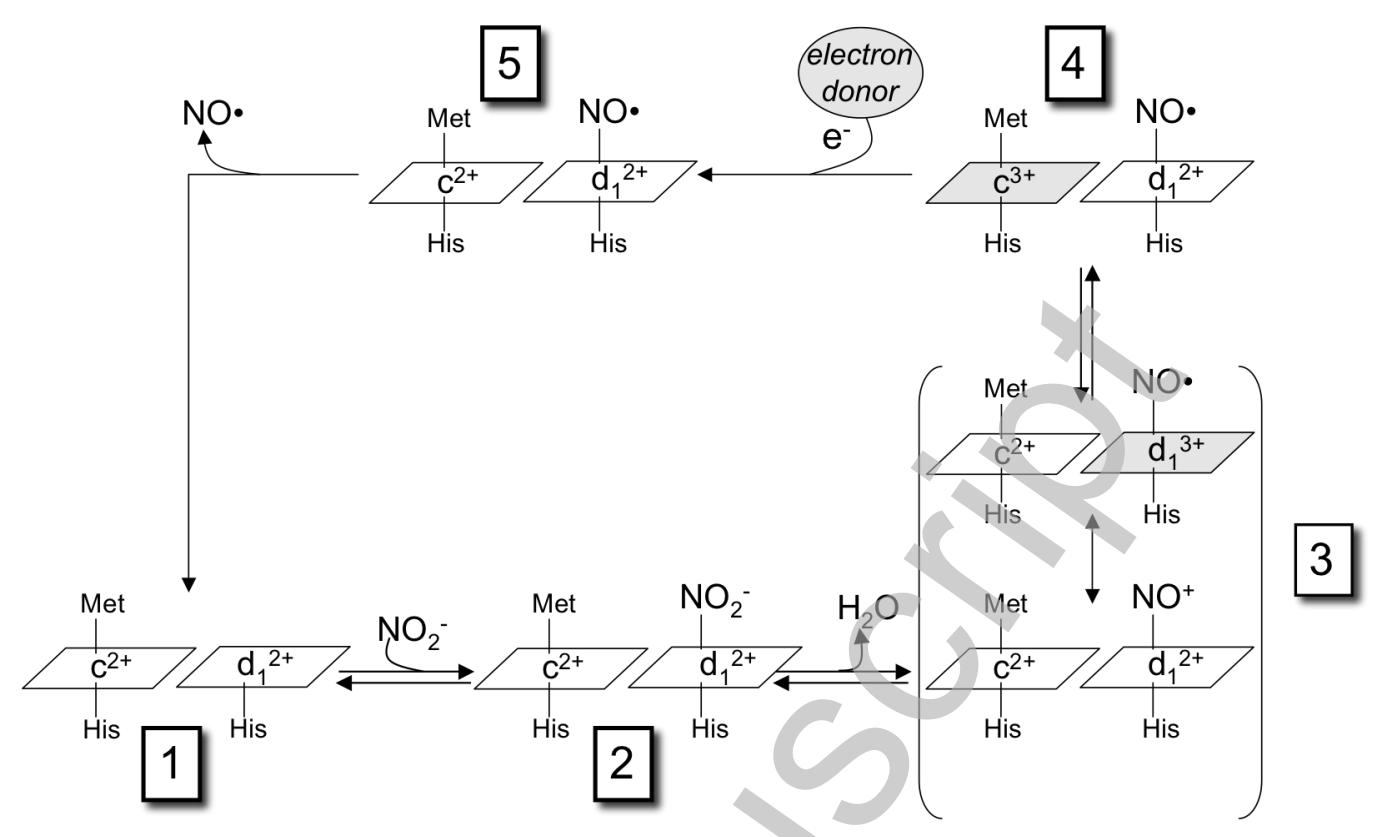

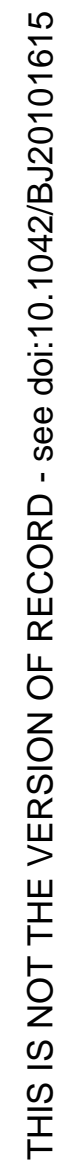

B

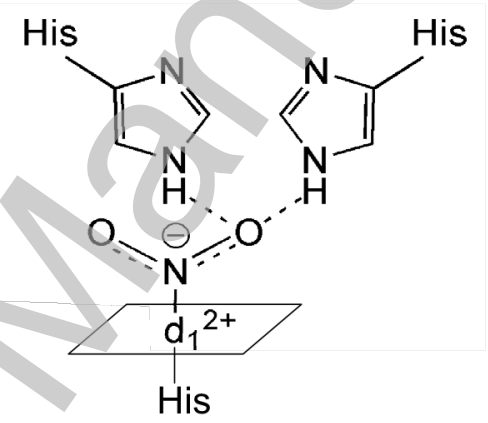

FIGURE 5 